\title{
Medium and High Fidelity Simulations in Training Undergraduate Nursing and Operating Room Students. Are They Effective?
}

\section{Farideh Yazdanpanah}

Shiraz University of Medical Sciences

\section{Azizallah Dehghan}

Fasa University of Medical Sciences

Leila Bazrafkan ( $D$ I.bazrafkan@yahoo.com )

Shiraz University of Medical Sciences

\section{Research Article}

Keywords: Nursing and OR Education, Medium- and High-Fidelity Simulators, OSCE.

Posted Date: January 4th, 2021

DOl: https://doi.org/10.21203/rs.3.rs-128520/v1

License: (c) (1) This work is licensed under a Creative Commons Attribution 4.0 International License.

Read Full License 


\section{Abstract}

Background: Simulators-Based Education is any type of educational activity that uses simulation of clinical scenarios to increase students' awareness and skills. Simulation environments are able to create a place for students to expand their competencies in specialized skills without posing a risk to patients. In simulation, an attempt is made to bring the learning conditions so close to the real conditions, so that the learned concepts can be transferred to the real world.

Methods: This is a quasi-experimental study. The statistical populations of the study were nursing and operating room (OR) students of Larestan University of Medical Sciences who were selected using census method. A total of 192 students participated in this study, which 96 students were in the control group and 96 students were in the experimental group. At the beginning of the study, students of both groups participated in the pre-test. In this study low-fidelity simulation was used to train control group, and in the experimental group training, medium- and high-fidelity simulation were applied. The post-test was performed after completion of the training program of both groups. 4 instruments were used for data collection. The data were analyzed using SPSS software (version 20.0).

Results: The results of this study showed that students in the experimental group scored significantly higher in knowledge domain compare to control group students, and also performed better in the objective structured clinical examination (OSCE) $(\mathrm{P}<0.001)$. Also, this study showed that the average total score of students' attitudes towards the role of simulators in the experimental group is higher than the control group. Statistical relationship was significant in some factors such as "patients' safety ( $P=$ 0.014)", "increasing the student's self-confidence $(P=0.041)$ ", "connecting the topics taught in the theoretical units $(P=0.024)$ ". Also, statistical relationship was meaningful in training with low-fidelity models which stated "it was not a reliable learning experience $(P=0.004)$ ".

Conclusions: Simulation is an effective method for better teaching-learning that can increase knowledge, improve clinical competence, feel more confident and integrate knowledge in a safe and controlled environment.

\section{Background}

Nursing education comprises pragmatic curricula that manifest both theoretical knowledge and applied skills. In skill-oriented learning strategies, where learning through practice plays a major role, ensuring the integration of theoretical knowledge into practice is of vital importance (1). The basic perspective of high quality nursing education programs elaborates the basic discipline of global standards (2). However, traditional teaching methods, in which the nursing education faculty facilitate training in a teachercentered approach, and the transmission of information solely relies on a one-way communication techniques, are no longer sufficient and efficient to meet the needs of the rapidly changing society (3). Such educational systems mainly lead to teaching methods in which students are not the focus, and as a result, it nurtures students who play a passive role in nursing practice. For this reason, curricula in nursing 
education need to be reformed in such a sense that provides students opportunities to take on a more active role. This requires application of more innovative approaches in the education system (4). In this context, simulations, advocated by so many scholars, provide an innovative teaching method. Simulation-Based Medical Education is any type of educational activity that uses the simulation of clinical scenarios to increase students' awareness and skills in workplace (5). In other words, simulation is a method that can be designed to reflect real-life conditions. By definition simulation replicates events and the related cases similar to the standards of a clinical environment (6). Simulation allows students to practice and learn their clinical skills and competence in a safe and anxiety-free environment. Normally it occurs with ease and without fear of making mistakes, until students are empowered with the sufficient skills, which will lead to better development of critical thinking and clinical decision-making skills. Additionally, simulation provides an educational method that encourages active learning to develop skills through repetition of events based on real-world scenarios (7). The World Health Organization (WHO) highly recommends the use of innovative methods such as simulation in nursing school education programs (2). Nursing practices are performed in complex and dynamic health settings; therefore, to succeed in their role in these environments it is essential that nurses be always exposed to well-designed educational experiences (8).

Basically there are five types of simulations applied in nursing education which are outlined in the following. Low-tech or static task trainer: This type of simulator does not respond to students and includes simple tools such as skin for stitching training. Complex task trainer simulation: Similar to CPR mannequin that has a sensor; in this type of simulator student receive feedbacks. Simulated patient: Refers to the role played by a classmate or other person in the patient's role. Screen-Based Computer Simulator: Is a process performed on a computer which is designed to predict the behavior of or the outcome of a real-world or physical system. It simulates a specific task or environment and also gives feedback to the student. Integrated Simulation: A combination of advanced computer technology and complete or partial body mannequins. One key point in applying simulators in educational training is the level of accuracy, also known as the level of realism. In terms of functionality, simulators are divided into three categories: low, medium/moderate, and high fidelity. Low-fidelity simulators are used to demonstrate skills and, in some cases, they are applied to enhance students' skills and practice. Simulations of medium-fidelity are used to teach more complex skills and are closer to reality, such as mimicking heart and lung sounds. In high-fidelity simulations healthcare education methodology involves the use of sophisticated life-like mannequins in realistic patient environments. More importantly, students receive physiological responses in high-fidelity simulations (9). A number of researches have been done to study simulators effects on different variables such as learning, knowledge level, clinical skills, selfconfidence, etc. using quantitative or qualitative schemes and or a combination of both. Kapucu (2017) ascertained that simulation-based education prepares nursing students for real clinical environments (10). Kim (2017) stated that critical thinking and clinical judgment were important and necessary characteristics of nurses to perform their professional tasks. Nursing students can develop clinical judgment skills and evaluate scenarios with the guidance of an instructor in a simulated training (11). Lin (2016) found that learning by simulation methods increases students' self-efficacy levels in relation to 
basic nursing skills (12). Lubbers and Rossman (2016) found that nursing students were very satisfied with the simulation experience (13). In their study Mohammed and Ahmed (2016), determined that simulation training increased satisfaction, self-confidence, and higher nursing skills (14). In his research, Bussard (2015) indicated that using simulation in nursing education increased patient safety and improved inter-professional expertise (15). Lindsey and Jenkins (2013) determined that nursing students who has received clinical simulation training intervention showed a higher level of clinical knowledge and judgment (16). Cordeau (2012) stated in her research that through simulated training, nursing students enhanced their self-confidence by performing appropriate nursing care and were promoted from a novice nursing student to a professional nurse (17). Wilson (2012) stated that simulation methods help nursing students gain more effective communication skills and critical thinking (18).

Nonetheless there are some education boards and faculty that claim instructors can teach all nursing skills without the need for sophisticated skill labs, and are content with simple mannequins in nursing training. Hence this study, conducted in Larestan University of Medical Sciences, underlines the role and concept of medium- and high-fidelity simulations, to shape nursing and OR undergraduate students' perspectives and clinical competence.

\section{Methods}

\section{Study design and participants}

The present quasi-experimental study was conducted during May-July 2020 at Larestan University of Medical Sciences. The research goals were investigating the effects of medium- and high-fidelity simulations in preparing Undergraduate Nursing and operating room (OR) students for clinical activities. In this regard, students' knowledge, skills and attitudes were evaluated.

Sampling: The statistical populations of the study were nursing and OR students of Larestan University of Medical Sciences who were selected using census method. Inclusion criteria included passing the theory lesson of nursing principles and skills for nursing students and passing the theory lesson of principles and techniques of clinical skills for OR students, and of course willingness to participate in the study. For each field, students enrolled in two specific academic year were consider as control group and students enrolled on other two academic year were consider as experimental group. A total of 192 students participated in this study, which 96 students were in the control group and 96 students were in the experimental group.

Data Collection instruments: 4 instruments were used for data collection.

Demographic information form which included student's personal profile such as gender and age, field and year of entry to university. A questionnaire containing 27 questions to assess students' attitude, which is based on the Likert scale, and there are five options for each question: strongly agree, agree, undecided, disagree, strongly disagree; that a score of 1 to 5 is awarded to them. For the validity and reliability of this questionnaire: first the English questionnaire was translated into Persian by 2 English 
language experts. Then the Persian version was translated into English by 2 other person and the original English questionnaire was matched with the questionnaire translated from the Persian version to confirm the accuracy of the translation. It was also culturally adapted. Then, the validity of the questionnaire was confirmed by five experts. The English questionnaire was provided to us by McCaughey Caroline S., the author of the article "The role of simulation in nurse education" (19). Student Knowledge Assessment Questionnaire, which consisted of 20 four-choice questions, which were assigned one point to the correct answer and zero point to wrong answer or no answer. Check list of objective structured clinical examination (OSCE) stations to assess students' skills, which included 5 stations. Station No 1. (Peripheral intravenous cannulation), Station No 2. (Nasogastric tube insertion), Station No 3. (Urinary catheter insertion), Station No 4. (Endotracheal intubation), Station No 5. (Cardiopulmonary resuscitation). The test score ranged from zero to 128 . Finally, the score obtained from the knowledge assessment questionnaire was added to the score obtained from the OSCE and then the score was calculated based on 20 .

\section{Procedure}

For each field, students enrolled in two specific academic year were consider as control group and students enrolled on other two academic year were consider as experimental group. A total of 192 students participated in this study, which 96 students were in the control group and 96 students were in the experimental group. The students were verbally informed of the purpose, context, and method of the research. Because of the special circumstances due to the prevalence of Corona virus (Covid-19), all the points of health protocols and physical distancing also were explained to the students. Written informed consent was obtained from the participants. The participants were assured that the information they provide to the research will be used only for the purpose of this research and their privacy will be protected. At the beginning of the study, students of both groups participated in the pre-test by implementing health protocols and physical distancing. In this way, first the demographic information forms were filled in by students and then the attitude questionnaires were given to them. After that, knowledge assessment questionnaires were given to students. Then, an OSCE was held to assess students' skill, which included 5 stations. Before entering the test site, students rested in a separate hall, and after explaining how to hold the test, 5 students were selected in each turn and each student entered a room (a station). After the specified time has elapsed, they left the station with the sound of the alarm clock and went to the next station in a clockwise direction, so that each student passed 5 stations and then they left the test site. Training started the day after the pre-test. In such a way that the students of both control and experimental groups were divided into smaller groups and two sessions were held every week for each small group lasting 2 hour, which trainings were conducted by several instructors in separate rooms and finally the total training lasted 8 weeks. In the control group, teaching the clinical skills of nursing and OR was done traditionally by presenting a lecture, Power Point presentation and using low-fidelity mannequins that had no the capability for providing feedback. In the experimental group, in addition to lectures and Power Point presentations, clinical skills training for nursing and OR student's was conducted at the clinical skills center and by using medium- and high-fidelity mannequins and models that had the capability for providing feedback. 
The clinical skills center, which was recently opened in Larestan University of Medical Sciences, consists of 12 rooms and has units of nursing, midwifery, operating room, anesthesia, medical emergencies, physical exam, conference room, practice room and locker room. Mannequins and models in the nursing unit: Advanced nursing mannequin, child nursing mannequin, blood pressure manual training model, nasal feeding training model, NG TUBE tracheostomy training model, bed wound care training model, female catheterized training model, arm model for veins extraction, Enema training model, surgical dressing torso model, arm for training IM and SQ injections, forearm model for intra-skin injections, pad for teaching cannulation, injection training pad (two veins), DC shock. Models in the emergency medical and anesthesia unit: ALS adult MEGA CODE mannequin with VITAL SIM, CPR child training mannequin with QCPR device, CPR adult training mannequin with intubation and shock capability, CHEST TUBE training model, choking training model, Top and lower body models for bandage training, seat belt, safety necklace, backpack, suction training model, $25 \mathrm{~kg}$ injured transport and rescue mannequin. Models in the OR and anesthesia unit: Adult intubation model with laryngeal spasm and suction capability, child intubation model, spinal injection training model, baby head model for vein training, arm model for suturing training, suture practice kit, Anesthesia machines, various kinds of surgical instruments. Models in the midwifery unit: maternal and neonatal simulation with cyanosis and CPR capability, Leopold maneuvering mannequin, measuring engagement of the fetal head model, cervical effacement and dilatation measurement training model, episiotomy training model, Ob/Gyn training model, family planning training model, IUD placement training model, child nursing mannequin (male and female), infant model for intubation and CPR with the umbilical catheter, delivery instrument set and episiotomy set, Doppler fetal monitor. In this center, clinical skills training for experimental group was done according to the purpose of the study and by using the relevant mannequins and models. Then students of the experimental group practiced on these mannequins and models. The practice method was such that while performing the technique by each member of the group, the other members evaluated her/his technique and discussed about it after completing and presented the necessary feedback to each other. Instructor monitored the students' performance at all stages and provided them with the necessary feedback. The book Clinical Skills Center, written and published by the first author of this article, was given to the students of the experimental group, in which purpose of establishing the clinical skills center, center's mannequins and models and how to work with them are explained. Throughout the study, necessary health protocols and physical distancing were fully observed and both groups passed the posttest after completing the trainings. The pre-test and post-test conditions were the same in different ways for students of both groups.

\section{Statistical analysis}

SPSS version 20 statistical software was used for data analysis. Mean and standard deviation were used to describe quantitative variables; Frequency and frequency percentage were used to describe qualitative variables. Independent t-test was used to compare the mean score of knowledge, attitude and skills between the two groups of intervention and control, as well as gender and field of study, and paired t-test was used to compare the mean score of knowledge, attitude and skills before and after the intervention. Chi-square test was also used to compare gender distribution, age group and field of study between the 
two groups. One-way analysis of variance was also used to compare the mean score of attitude between age groups. $\mathrm{P}<0.05$ was considered statistically significant.

\section{Ethical considerations}

The present study was approved by the Ethics Committee of Shiraz University of Medical Sciences, Shiraz, Iran (code: IR.SUMS.REC.1399.740). The students were verbally informed of the purpose, context, and method of the research. Because of the special circumstances due to the prevalence of Corona virus (Covid-19), all the points of health protocols and physical distancing also were explained to the students. Written informed consent was obtained from the participants. The participants were assured that the information they provide to the research will be used only for the purpose of this research and their privacy will be protected.

\section{Results}

The results showed that $64.6 \%$ of the students in the control group were male and $35.4 \%$ were female and in the experimental group $45.8 \%$ were male and $54.2 \%$ were female. There was a significant difference between the control and experimental groups concerning their gender $(P=0.009)$. Most of the students participating in the control and experimental group were 18-22 years old, so that $62.5 \%$ in the control group and $86.5 \%$ in the experimental group were 18-22 years old. There was also a significant difference between the two groups concerning the participants' age $(P=0.002)$. Out of a total of 96 students in the control group, 73 students (0.76\%) were studying nursing and $24 \%$ were studying OR, while in experimental group $72.9 \%$ of students were studying nursing and $27.1 \%$ were studying OR. There was no significant difference between the two groups of experimental and control in terms of their field of study $(P=0.619)$.

Comparison of the mean grade point average obtained in the domains of knowledge and skills of students in the control and experimental groups, before and after the intervention, showed that a statistically significant difference between the two groups $(P<0.001)$. The results of Table 1 showed that students in the experimental group scored significantly higher in knowledge domain compare to control group students, and also performed better in the OSCE (Table 1).

Table 1

Comparison of the mean grade point average obtained in the domains of knowledge and skills of students in the control and experimental groups, before and after the intervention

\begin{tabular}{|c|c|c|c|c|c|c|c|}
\hline \multirow[t]{2}{*}{ Group } & \multicolumn{2}{|c|}{ Prior intervention } & \multicolumn{2}{|c|}{ After invention } & \multicolumn{2}{|c|}{ Mean difference } & \multirow{2}{*}{$\begin{array}{l}\text { P. } \\
\text { Value }\end{array}$} \\
\hline & Mean & $\begin{array}{l}\text { Standard } \\
\text { deviation }\end{array}$ & Mean & $\begin{array}{l}\text { Standard } \\
\text { deviation }\end{array}$ & Mean & $\begin{array}{l}\text { Standard } \\
\text { deviation }\end{array}$ & \\
\hline Control & 13.84 & 1.35 & 13.08 & 1.28 & 4.32 & 0.52 & 0.393 \\
\hline Experimental & 13.76 & 1.16 & 18.08 & 1.04 & 0.045 & 0.58 & $\triangle 0.001$ \\
\hline P-value & 0.655 & & $\bowtie 0.001$ & & $\bowtie 0.001$ & & \\
\hline
\end{tabular}


Considering that the range of scores assigned to each attitude question varies from 1 to 5 , so the minimum score of each person in the control and experimental group is 27 and maximum score will be 135; therefore, the average score of the answer to each question was used to report the score of each question (Table 2). 
Table 2

Comparison of students' attitude in the two groups towards the roll of simulator in student's preparation, after the intervention

\begin{tabular}{|c|c|c|c|c|c|c|c|c|}
\hline \multirow[t]{2}{*}{ row } & \multirow{2}{*}{$\begin{array}{l}\text { Group } \\
\text { Variable }\end{array}$} & \multicolumn{2}{|c|}{ Control Group } & \multicolumn{2}{|c|}{$\begin{array}{l}\text { Experimental } \\
\text { Group }\end{array}$} & \multicolumn{2}{|l|}{ Total } & \multirow[t]{2}{*}{$\begin{array}{l}\mathrm{P}- \\
\text { Value }\end{array}$} \\
\hline & & Mean & $\begin{array}{l}\text { Standard } \\
\text { deviation }\end{array}$ & Mean & $\begin{array}{l}\text { Standard } \\
\text { deviation }\end{array}$ & Mean & $\begin{array}{l}\text { Standard } \\
\text { deviation }\end{array}$ & \\
\hline 1 & $\begin{array}{l}\text { A helpful } \\
\text { educational } \\
\text { experience for } \\
\text { managing a } \\
\text { patient's treatment }\end{array}$ & 4.31 & 0.825 & 4.35 & 0.711 & 4.33 & 0.768 & 0.991 \\
\hline 2 & $\begin{array}{l}\text { Enhancing patient } \\
\text { safety }\end{array}$ & 3.86 & 0.913 & 4.17 & 0.854 & 4.02 & 0.895 & 0.014 \\
\hline 3 & $\begin{array}{l}\text { Better decision } \\
\text { making in a clinical } \\
\text { setting }\end{array}$ & 3.84 & 1.040 & 3.71 & 1.085 & 3.78 & 1.062 & 0.366 \\
\hline 4 & $\begin{array}{l}\text { The learning } \\
\text { experience was } \\
\text { unreliable }\end{array}$ & 3.46 & 1.132 & 2.99 & 1.091 & 3.22 & 1.133 & 0.004 \\
\hline 5 & More responsibility & 3.96 & 0.807 & 3.94 & 0.892 & 3.95 & 0.848 & 0.955 \\
\hline 6 & $\begin{array}{l}\text { Efficient to develop } \\
\text { from nursing } \\
\text { student to nursing } \\
\text { staff }\end{array}$ & 3.55 & 0.983 & 3.47 & 1.142 & 3.51 & 1.063 & 0.824 \\
\hline 7 & $\begin{array}{l}\text { Getting the } \\
\text { organizational skill } \\
\text { of a registered } \\
\text { nurse }\end{array}$ & 3.61 & 0.899 & 3.63 & 1.069 & 3.62 & 0.985 & 0.910 \\
\hline 8 & $\begin{array}{l}\text { More certainty in } \\
\text { clinical diagnoses }\end{array}$ & 3.49 & 1.036 & 3.61 & 1.146 & 3.55 & 1.091 & 0.358 \\
\hline 9 & $\begin{array}{l}\text { Competence to } \\
\text { assess a patient's } \\
\text { condition }\end{array}$ & 3.69 & 0.921 & 3.59 & 1.236 & 3.64 & 1.088 & 0.840 \\
\hline 10 & $\begin{array}{l}\text { Schedule patient } \\
\text { care more efficiently }\end{array}$ & 3.66 & 0.961 & 3.61 & 1.173 & 3.64 & 1.070 & 0.933 \\
\hline 11 & $\begin{array}{l}\text { Increase the ability } \\
\text { to provide } \\
\text { comprehensive care }\end{array}$ & 3.95 & 0.851 & 3.99 & 1.010 & 3.97 & 0.932 & 0.479 \\
\hline 12 & $\begin{array}{l}\text { Evaluation of prior } \\
\text { care provided to the } \\
\text { patient }\end{array}$ & 3.75 & 0.846 & 3.85 & 0.995 & 3.80 & 0.922 & 0.305 \\
\hline
\end{tabular}




\begin{tabular}{|c|c|c|c|c|c|c|c|c|}
\hline \multirow[t]{2}{*}{ row } & \multirow{2}{*}{$\begin{array}{l}\text { Group } \\
\text { Variable }\end{array}$} & \multicolumn{2}{|c|}{ Control Group } & \multicolumn{2}{|c|}{$\begin{array}{l}\text { Experimental } \\
\text { Group }\end{array}$} & \multicolumn{2}{|l|}{ Total } & \multirow[t]{2}{*}{$\begin{array}{l}\mathrm{P} \text { - } \\
\text { Value }\end{array}$} \\
\hline & & Mean & $\begin{array}{l}\text { Standard } \\
\text { deviation }\end{array}$ & Mean & $\begin{array}{l}\text { Standard } \\
\text { deviation }\end{array}$ & Mean & $\begin{array}{l}\text { Standard } \\
\text { deviation }\end{array}$ & \\
\hline 13 & $\begin{array}{l}\text { Boost confidence in } \\
\text { dealing with the } \\
\text { actual patients }\end{array}$ & 3.70 & 1.027 & 3.97 & 1.031 & 3.83 & 1.035 & 0.041 \\
\hline 14 & $\begin{array}{l}\text { Increasing students' } \\
\text { esteem as a } \\
\text { member of the } \\
\text { treatment team }\end{array}$ & 3.72 & 0.855 & 3.75 & 1.005 & 3.73 & 0.931 & 0.577 \\
\hline 15 & $\begin{array}{l}\text { More worries about } \\
\text { the future job }\end{array}$ & 3 & 1.161 & 3.14 & 1.253 & 3.07 & 1.207 & 0.527 \\
\hline 16 & $\begin{array}{l}\text { Training was not } \\
\text { realistic based on } \\
\text { clinical conditions }\end{array}$ & 3.33 & 1.063 & 3.55 & 1.104 & 3.44 & 1.086 & 0.183 \\
\hline 17 & $\begin{array}{l}\text { Helped the student } \\
\text { find the connection } \\
\text { between the topics } \\
\text { learnt in the } \\
\text { theoretical units }\end{array}$ & 3.67 & 0.970 & 3.97 & 0.945 & 3.82 & 0.967 & 0.024 \\
\hline 18 & $\begin{array}{l}\text { Learning from } \\
\text { mistakes }\end{array}$ & 3.84 & 0.910 & 3.98 & 1.086 & 3.91 & 1.001 & 0.122 \\
\hline 19 & $\begin{array}{l}\text { Useful training for } \\
\text { working in clinic }\end{array}$ & 3.89 & 0.893 & 4.05 & 1.019 & 3.97 & 0.959 & 0.077 \\
\hline 20 & $\begin{array}{l}\text { It had no effect on } \\
\text { clinical diagnoses }\end{array}$ & 3.03 & 1.147 & 2.88 & 1.117 & 2.95 & 1.132 & 0.290 \\
\hline 21 & $\begin{array}{l}\text { Identify areas that } \\
\text { need to be } \\
\text { strengthened in } \\
\text { practice }\end{array}$ & 3.61 & 1.009 & 3.77 & 1.061 & 3.69 & 1.036 & 0.250 \\
\hline 22 & $\begin{array}{l}\text { Improving } \\
\text { communication } \\
\text { skills }\end{array}$ & 3.46 & 1.178 & 3.44 & 1.195 & 3.45 & 1.183 & 0.919 \\
\hline 23 & $\begin{array}{l}\text { Increasing the range } \\
\text { of skills required by } \\
\text { a nursing student }\end{array}$ & 3.72 & 1.023 & 3.71 & 1.169 & 3.71 & 1.096 & 0.839 \\
\hline 24 & $\begin{array}{l}\text { Effective in } \\
\text { assessing the } \\
\text { patient's condition }\end{array}$ & 3.57 & 1.013 & 3.77 & 1.031 & 3.67 & 1.024 & 0.180 \\
\hline 25 & $\begin{array}{l}\text { Compatibility with } \\
\text { team skills }\end{array}$ & 3.26 & 1.069 & 3.46 & 1.222 & 3.36 & 1.149 & 0.204 \\
\hline
\end{tabular}




\begin{tabular}{|c|c|c|c|c|c|c|c|c|}
\hline \multirow[t]{2}{*}{ row } & \multirow{2}{*}{$\begin{array}{l}\text { Group } \\
\text { Variable }\end{array}$} & \multicolumn{2}{|c|}{ Control Group } & \multicolumn{2}{|c|}{$\begin{array}{l}\text { Experimental } \\
\text { Group }\end{array}$} & \multicolumn{2}{|l|}{ Total } & \multirow[t]{2}{*}{$\begin{array}{l}\text { P- } \\
\text { Value }\end{array}$} \\
\hline & & Mean & $\begin{array}{l}\text { Standard } \\
\text { deviation }\end{array}$ & Mean & $\begin{array}{l}\text { Standard } \\
\text { deviation }\end{array}$ & Mean & $\begin{array}{l}\text { Standard } \\
\text { deviation }\end{array}$ & \\
\hline 26 & $\begin{array}{l}\text { Made students } \\
\text { anxious about } \\
\text { changing from a } \\
\text { nursing students to } \\
\text { nursing staff }\end{array}$ & 2.97 & 1.156 & 2.94 & 1.177 & 2.95 & 1.164 & 0.730 \\
\hline 27 & $\begin{array}{l}\text { Positive impact on } \\
\text { student confidence } \\
\text { to act as a nurse. }\end{array}$ & 3.66 & 1.065 & 3.77 & 1.183 & 3.71 & 1.124 & 0.303 \\
\hline
\end{tabular}

The mean scores of students' attitudes towards the role of simulators before and after the intervention were not significantly different between the control and experimental groups. Findings of this study indicated that the average total score of students' attitude towards the role of simulators in the experimental group is higher than the control group; however, it is not statistically significant (Table 3).

Table 3

Comparison of students' attitudes in the two groups towards the role of simulators in students' preparation, before and after the intervention

\begin{tabular}{|llllllll|}
\hline Group & \multicolumn{2}{l}{ Prior intervention } & \multicolumn{2}{c}{ After invention } & \multicolumn{2}{c|}{ Mean difference } & P- \\
\cline { 2 - 7 } & Mean & $\begin{array}{c}\text { Standard } \\
\text { deviation }\end{array}$ & Mean & $\begin{array}{l}\text { Standard } \\
\text { deviation }\end{array}$ & Mean & $\begin{array}{l}\text { Standard } \\
\text { deviation }\end{array}$ & \\
\hline Control & 97.43 & 11.36 & 97.56 & 13.69 & 0.13 & 12.22 & 0.943 \\
\hline Experimental & 97.98 & 13.61 & 99.05 & 16.55 & 1.07 & 14.29 & 0.612 \\
\hline P-value & 0.788 & & 0.538 & & 0.624 & & \\
\hline
\end{tabular}

The total means of the answers to the attitude questions towards the role of simulators in the students' preparation in two groups of male and female students were $97.12 \pm 13.35$ and $99.76 \pm 17.11$ respectively. The results of Table 4 indicated that there is no significant difference between the two groups of male and female students in terms of answering the attitude questions of simulators' role $(\mathrm{P}=$ 0.231) (Table 4).

Table 4

Comparison of students' attitude in the two groups towards the role of simulators in students' preparation,

by gender

\begin{tabular}{|llll|}
\hline Gender & Mean & Standard deviation & P-Value \\
\hline Male & 97.1226 & 13.35501 & 0.231 \\
Female & 99.7674 & 17.11255 & \\
\hline
\end{tabular}


Comparison of the total means of the answers given to the attitudes questions to the role of simulators for preparing students in age categories according to the Table 5 indicated that there is no significant difference between age categories in terms of answering attitude questions to the role of simulators $(\mathrm{P}=$ 0.05) (Table 5).

Table 5

Comparison of students' attitude in the two groups towards the role of simulators in students' preparation, by age

\begin{tabular}{|llll|}
\hline Age(year) & Mean & Standard deviation & P-Value \\
\hline 18-22 & 97.6853 & 15.97420 & 0.050 \\
& 100.2791 & 11.35431 & \\
& 91.8000 & 11.41052 & \\
\cline { 1 - 3 } 35 years and older & 135.0000 & 0 & \\
\cline { 1 - 3 } Total & 98.3073 & 15.16935 & \\
\hline
\end{tabular}

The total means of the answers given to the attitude questions towards the role of simulators for preparing students in the two groups of nursing and OR students were $95.86 \pm 14.93$ and $105.42 \pm 13.63$ respectively, the results of Table 6 indicated that there is a significant difference between nursing and OR students in terms of answering attitude questions to the role of simulators $(P<0.001)$. The results of table below show that OR students has had a significantly better attitude towards the role of simulators (Table 6).

Table 6

Comparison of students' attitude in the two groups towards the role of simulators in students' preparation, by field of study

\begin{tabular}{|llll|}
\hline Field & Mean & Standard deviation & P-Value \\
\hline Nursing & 95.8671 & 14.93990 & 0.000 \\
\cline { 1 - 3 } OR & 105.4286 & 13.63207 & \\
\hline
\end{tabular}

\section{Discussion}

In the present study, the effect of simulators with intermediate- and high-fidelity was investigated in preparing undergraduate nursing and OR students for clinical work. The results of this study showed that students in the experimental group scored significantly higher in knowledge domain compare to control group students, and also performed better in the OSCE. Kim (2017) indicated in his study that students had a higher degree of academic success, skill and clinical competence in the educational method of simulation (11). Rode et al. (2016) showed in their research that students of intervention group who received nursing training with the method of simulation were significantly better in the knowledge domain 
(knowledge retention) than students of control group who received their education through traditional teaching strategies (20). Edeer and Sarikaya (2015) have declared in their research that simulation is a preferred educational method for nursing students in acquiring knowledge, skills development and improving the clinical skills (6). Mohamed Soliman et al. (2014) indicated in their study that nursing students in the experimental group who were taught using the simulation method had higher scores in knowledge and skills' domain than the control group (21). Liaw et al. (2012) showed in their research that nursing students have improved their knowledge and performance in simulation method compare to other methods (22). The results of all these researchers are consistent with the results of this study.

In line with the purpose of study in attitude's domain, the findings of this study showed that the average total score of students' attitudes towards the role of simulators in the experimental group is higher than the control group, and convincingly states the effect of using these simulators as a valuable learning method that has had a positive effect on the clinical efficiency of nursing and OR students. The study found that training with advanced models, improved patients' safety, and students made less mistakes dealing with real patients. Ozkal and Cayir's findings (2016) nursing students stated that the simulation method, by providing life-like opportunities was effective to increase their practice skills. Participants also stated that the simulation method allowed them to gain invaluable experiences without harming patients and mastered new skills by learning from their mistakes (23). In line with Bussard (2015), Handwerker (2012) and Brady's findings (2011) simulators improved patients' safety $(15,24,25)$. McCaughey et al. (2010) determined that high-fidelity simulation enable students to increase their skills associated with patients' safety (19). Hovancsek et al. (2009) believe that the most important reason for using the simulation method in nursing is preparing nurses for critical situations as well as patients' safety (26). The results of all these researchers are consistent with the results of this study. Since nursing students chiefly experience their clinical practice in a real environment, insufficient skills can incur sever physical and mental harm to patients. Therefore, to ensure patients' safety, it necessitates that nursing education methods be designed in a sense that students be able to acquire the adequate nursing skills in a life-like clinical environment $(27,28)$. In this regards simulated patient and mannequins can reduce anxiety and facilitate the students' skill acquisition. Simulations also, reduce students' errors and therefore, the likelihood of patients harm can significantly be reduced and can be used at all levels of nursing education (29-31). Concerning patients' safety, it is envisaged that simulations in nursing education be expanded even more in the coming years. Our results showed that students who trained with advanced models felt more confident with the same conditions they encountered as a novice in real clinical situations. Kaddoura et al. (2016) showed in their study that using high-fidelity simulation is effective in promoting critical thinking, self-confidence and student competence (32). All these researchers including Lucas (2014), Tosterud et al. (2013), Thidemann and Soderhamn (2013), Aebersold et al. (2013), Jeffries (2012), Oldenburg (2012) showed in their research that using simulators increased nursing students' selfconfidence (33-38). Norman et al. (2012) maintained that self-confidence was an integral result of the simulation experience (39). McCaughey et al. (2010) also showed in their research that high-fidelity simulations in increase student's self-confidence (19). Simulations give student's opportunity to actively participate in learning process (30). The findings of all these researches are consistent with the findings 
of this study. Students in this study also showed that using advanced models helped them to understand the correspondence between topics taught in theoretical units. Kaddoura et al. (2016) showed in their study that the use of high-fidelity simulation was effective in integrating theory and practice and knowledge recognition (32). Also, Oermann and Gaberson (2014), Yuan et al. (2014), Gates et al. (2012), Liaw et al. (2012), in their research determined that simulators led to integration of theory and practice, which improves the application of theory to practice with no risk in a safe environment $(40-42,22)$. Mould et al. (2011) showed positive feedback from nursing students, such as: learning through simulation is fun and valuable, and it helps them to grasp the connection between theory and practice (43). Kaddoura (2010) found that simulation contributed to link theory and practice. Simulations help students to relate what they learn in the class to what they encounter in the clinical or patient care environment (44). McCaughey et al. (2010) also showed in their research that high-fidelity simulators are useful for correlation between theoretical units and performance. $87 \%$ of students participated in McCaughey's study reported simulators contributed to understand the relationship between theoretical components of nursing curriculum (19). These findings also are in line to this study. In recent years, due to the profound gap between theoretical knowledge and clinical practice, we are witnessing nursing students in spite of the fact that they have acquired outstanding theoretical knowledge, are not able to efficiently apply their knowledge into practice in actual clinical environments (45-47). It is a worldwide fact that nursing quality services credits nursing science and profession. In this viewpoint it is necessary that medical schools provide opportunities to link theoretical knowledge and skilled competence so that nursing students can gain useful experiences. In other words nursing students need new educational methods that allow students to take on more active roles and receive appropriate feedbacks. Simulation, to fulfill such goals, provides an opportunity for the student to experience their clinical practice in a lifelike environment and transmits theoretical knowledge into a variety of psychomotor skills. Simulation techniques in fact can act as a bridge between theoretical content and clinical practice, providing students with the opportunity to learn new skills under supervision without endangering themselves or others (48). In simulation, an attempt is made to bring the learning conditions so close to the real conditions in a way the learned concepts become transferable to the real world. There is a kind of causeeffect correlation between the qualitative-quantitative aspects of nursing training and clinical competence. In this view the more efficient the learning methods today, the more competence future nurses will be ensured for the health public. We found that students in the control group, having higher mean scores and a statistically significant relationship, showed that training with low-fidelity simulation was not a reliable learning experience. Baptista et al. (2016) recognized that nursing students think a high-fidelity simulation helped them to better evaluate the patient and make decisions, and that highfidelity simulation was more realistic (49).

Finally, it is noteworthy to mention that it is not only students but faculty members need training to use the equipment and simulation experience. It is essential that faculty members be able to use technology and recognize the challenges in this area. Pazargadi et al. (2011) stated that knowledge and awareness of faculty members in various fields such as nursing, education, research, management and administration, foreign language and computer, affect their performance (27). In 2014, a prominent 
national study by the NCSBN showed that nursing education programs could replace up to $50 \%$ of traditional clinical practice with simulation, provided that factors such as faculty members who have been formally trained in simulation, a sufficient number of faculty members to support students, experts who conduct theoretical thinking, and equipment to create a realistic environment be included in the project (50).

\section{Application of research findings}

It is hoped that the results of this study will be used in the planning of training courses for students in the fields of nursing, operating room, midwifery, medicine, etc., which are closely related to patients, as well as training of health and medical staff who have an important responsibility in providing high quality services.

\section{Study limitations}

One of the limitations of this study was the high cost of medium- and high-fidelity simulations. The study considered the situations only at one of the country's nursing schools, and more likely results may be different concerning other universities' conditions.

\section{Conclusion}

In implementation of training by simulation method, if medium- and high-fidelity mannequins and models are used and the necessary care is taken in designing scenarios, the results will be more effective. There are some challenges in using this method that can be resolved to a large extent with proper planning. Educational institutions can develop and expand simulation programs based on a general understanding of the technology and educational potential of this method. Despite the problems, the simulation training method by using advanced mannequins and models, has many advantages and can increase knowledge and improve clinical competence. It is also a unique and effective way to increase safety and security of patient, increasing the student's sense of self-confidence, connecting the subjects taught in the theoretical units. Due to special emphasis that nursing knowledge has on ensuring patient safety and security, using this method in students' education in nursing schools seems necessary; and it should be included in the curriculum of nursing students with more emphasis so that we can contribute to the scientific development and consolidation of nursing knowledge and ultimately ensure health of the community by training more skilled and capable nurses.

\section{List Of Abbreviations}

WHO: World Health Organization

OR: Operating Room

OSCE: Objective Structured Clinical Examination 


\section{Declarations}

\section{Ethics approval and consent to participate}

The present study was approved by the Ethics Committee of Shiraz University of Medical Sciences, Shiraz, Iran (code: IR.SUMS.REC.1399.740). The participants were informed about the research goals and procedures. Also, the confidentiality of any disclosed information was guaranteed and voluntary participation was emphasized. Written informed consent was obtained from the participants. All methods were performed in accordance with the relevant guidelines and regulations.

\section{Funding}

The present article was extracted from a thesis written by Farideh Yazdanpanah. The design and implementation of the project was financially supported by Shiraz University of Medical Sciences, Shiraz, Iran (Grant No. 20876).

\section{Authors' contributions}

Farideh Yazdanpanah participated in the design of the study, acquisition, analysis, interpretation of data, manuscript drafting, and final approval of the version to be published. Leila Bazrafkan supervised the study and participated in the design of the study, analysis, and interpretation of data, and proofreading the manuscript. Azizallah Dehghan was involved in the design of the study, analysis, interpretation of data, and proofreading the manuscript. All authors have read and approved the final manuscript.

\section{Authors' information}

FY Medical Education Student, Medical Education Department, Medical School, Shiraz University of Medical Sciences, Shiraz, Iran.

LB is an Assistant Professor, Clinical Education Research Centre, Education Developmental Centre, Shiraz University of Medical Sciences, Shiraz, Iran.

AD is an Assistant Professor, Non-communicable Diseases Research Center, Fasa University of Medical Sciences, Fasa, Iran.

\section{Consent for publication}

Not applicable

\section{Availability of data and materials}

The datasets generated and analyzed during the current study are not publicly available due to confidentiality of the identity of the participants. Data are however available from the authors upon reasonable request. 


\section{Competing interests}

The authors declare that they have no conflict of interest.

\section{Acknowledgement}

The authors consider it necessary to thank Dr. Caroline S. McCaughey, Faculty of Medicine, Health and Life Sciences, Queen's University Belfast for sending her questionnaire. Also, we sincerely thank all the nursing and OR students who patiently participated in this research.

\section{References}

1. Eyikara E, Baykara GZ. The importance of simulation in nursing education. World Journal on Educational Technology. 2017; 9(1): 02-07.

2. World Health Organization. Nursing \& Midwifery Human Resources for Health. Global standards for the initial education of professional nurses and midwives. World Health Organization, Department of Human Resources for Health. 2009 Geneva: 3-36.

3. Fanning RM, Gaba DM. The role of debriefing in simulation-based learning. Society for simulation in Healthcare. 2007; 2(2): 115-125.

4. Dil S, Uzun M, Aykanat B. Innovation in nursing education. International Journal of Human Sciences. 2012; 9(2): 1217-1228.

5. Dent AJ, Harden MR. A practical guide for medical teachers. 2nd ed. Philadelphia: Elsevier publishing. 2005: 211-220.

6. Edeer AD, Sarikaya A. The use of simulation in nursing education and simulation types/Hemsirelik egitiminde simulasyon kullanimi ve simulasyon tipleri. Journal of Education and Research in Nursing. 2015 May 1; 12(2): 121-6.

7. Lavoie P, Clarke SP. Simulation in nursing education. Nursing management. 2017 Feb 1; 48(2): 16-7.

8. Najjar RH, Lyman B, Miehl N. Nursing students' experiences with high-fidelity simulation. International Journal of Nursing Education Scholarship. 2015 Jan 1; 12(1): 27-35.

9. Hayden J. Use of simulation in nursing education: national survey results. Journal of Nursing Regulation. 2010; 1(3): 52-57.

10. Kapucu S. The effects of using simulation in nursing education: A thorax trauma case scenario. International Journal of Caring Sciences. 2017 May 1; 10(2): 1069.

11. Kim M, Kim S. Debriefing practices in simulation-based nursing education in South Korea. Clinical Simulation in Nursing. 2017 May 1; 13(5): 201-9.

12. Lin HH. Effectiveness of simulation-based learning on student nurses' self-efficacy and performance while learning fundamental nursing skills. Technology and Health Care. 2016 Jan 1; 24(s1): S369375 . 
13. Lubbers J, Rossman C. The effects of pediatric community simulation experience on the selfconfidence and satisfaction of baccalaureate nursing students: a quasi-experimental study. Nurse Educ Today. 2016 Apr 1; 39: 93-98.

14. Mohammed SA, Ahmed HM. The effect of simulation training on nurses and intern nursing students' skill, confident and satisfaction regarding neonatal resuscitation. IOSR Journal of Nursing and Health Science. 2016; 5(5): 17-27.

15. Bussard ME. High-Fidelity Simulation to Teach Accountability to Prelicensure Nursing Students. Clinical Simulation in Nursing. 2015; 11(9): 425-430.

16. Lindsey $\mathrm{PL}$, Jenkins S. Nursing students' clinical judgment regarding rapid response: the influence of a clinical simulation education intervention. In Nursing Forum. 2013 Jan; 48(1): 61-70.

17. Cordeau MA. Linking the transition: A substantive theory of high-stakes clinical simulation. Advances in Nursing Science. 2012 Jul 1; 35(3): E90-102.

18. Wilson RD, Klein JD. Design, implementation and evaluation of a nursing simulation: a design and development research study. The Journal of Applied Instructional Design. 2012; 2(1): 57-68.

19. McCaughey CS, Traynor MK. The role of simulation in nurse education. Nurse Education Today. 2010; 30: 827-832.

20. Rode JL, Callihan ML, Barnes BL. Assessing the value of large group simulation in the classroom. Clinical simulation in nursing. 2016; 12(7): 251-259.

21. Mohamed Soliman HM, Mohamed sheble A, Ismaiel Shrief W. Effectiveness of Simulation training on clinical Nursing Education and competence: A Randomized Controlled Trial. International Journal of Advanced Research. 2014; 2(4): 387-393.

22. Liaw S, Scherpbier A, Rethans J, Klainin-Yobas P. Assessment for simulation learning outcomes: a comparison of knowledge and self-reported confidence with observed clinical performance. Nurse Educ Today. 2012 Aug; 32(6): e35-9.

23. Ozkal F, Cayir A. Opinions of nursing students towards simulation efficiency in nursing education. International Journal of Humanities and Social Science Invention. 2016; 5(12): 32-36.

24. Handwerker S. Transforming nursing education: a review of current curricular practices in relation to Benner's latest work. International journal of nursing education Scholarship. 2012; 9(1).

25. Brady D. Using Quality and Safety Education for Nurses (QSEN) as a pedagogical structure for course redesign and content. International Journal of Nursing Education Scholarship. 2011; 8(1).

26. Hovancsek M, Jeffries PR, Escudero E, Foulds BJ, Husebo SE, et al. Creating simulation communities of practice: An international perspective. Nurs Educ Perspect. 2009; 30(2): 121-5.

27. Pazargadi M, Sadeghi R. Simulation in nursing education. Edu Strategy Med Sci. 2011;3(4): 161167.

28. Zaghari Tafreshi M, Rasouli M, Sajadi M. Simulation in nursing education: A review article. IJME. 2013; 12(11): 888-894. 
29. Ricketts $B$. The role of simulation for learning within pre-registration nursing education. Nurse Education Today. 2011; 31(7): 650-654.

30. Maas NA, Flood LS. Implementing High-Fidelity Simulation in Practical Nursing Education. Clinical Simulation in Nursing. 2011; 7(6): 229-35.

31. Smith SJ, Roehrs CJ. High-fidelity simulation: Factor correlated with nursing student satisfaction and self-confidence. Nursing Education Perspectives. 2009; 30(2): 74-78.

32. Kaddoura M, Vandyke O, Smallwood CH, Gonzalez KM. Perceived benefits and challenges of repeated exposure to high fidelity simulation experiences of first degree accelerated bachelor nursing students. Nurse Educ today. 2016 Jan; 36: 298-303.

33. Lucas A. Promoting continuing competence and confidence in nurses through high-fidelity simulation-based learning. The Journal of Continuing Education in Nursing. 2014 July; 45(8): 1-6.

34. Tosterud R, Hedelin B, Louise Hall-Lord M. Nursing students' perceptions of high- and low-fidelity simulation used as learning methods. Nurse Educ Pract. 2013 Jul; 13(4):262-70.

35. Thidemann IJ, Soderhamn 0 . High-fidelity simulation among bachelor students in simulation groups and use of different roles. Nurse Education Today. 2013; 33: 1599-1604.

36. Aebersold M, Tschannen D. Simulation in nursing practice: the impact on patient care. OJIN: The Online J Issues Nurs. 2013 May 31; 18(2): 6.

37. Jeffries PR. Simulation in nursing education: from conceptualization to evaluation (2nd ed). National league for Nursing, New York, NY 2012: 25-42.

38. Oldenburg NL, Brandt K, Maney C, Selig K. Student-created scenarios in the high-fidelity simulation laboratory. Journal of Nursing Education. 2012; 51: 702-706.

39. Norman G, Dore K, Grierson L. The minimal relationship between simulation fidelity and transfer of learning. Medical Education. 2012; 46(7): 636-647.

40. Oermann M, Gaberson K. Evaluation and testing in nursing education (4th ed). New York: Springer. 2014

41. Yuan $\mathrm{H}$, Williams $\mathrm{B}$, Man $\mathrm{C}$. Nursing students' clinical judgment in high-fidelity simulation based learning: A quasi-experimental study. Journal of Nursing Education and Practice. 2014; 4(5).

42. Gates M, Parr M, Hughen J. Enhancing nursing knowledge using high-fidelity simulation. J Nurs Educ. 2012 Jan; 51(1): 9-15.

43. Mould J, White $\mathrm{H}$, Gallagher R. Evaluation of a critical care simulation series for undergraduate nursing students. Contemp Nurse. 2011; 38(1-2): 180 - 90.

44. Kaddoura M. New graduate nurses' perceptions of the effects of clinical simulation on their critical thinking, learning, and confidence. Contin Educ Nurs. 2010 Nov; 41(11): 506-16.

45. Memarian R, Kavosi A, Vanaki Z, Nasiri H, Hesam M. Effect of Competency-based-Training Program on Resuscitation Outcomes. Jgbfnm 2014; 11(2): 22-30.

46. Elahi N, Alhani F, Ahmadi F. Effective Education: Perceptions and Experiences of Nursing Students. IJME. 2012; 12(2): 110-119. 
47. Hassankhani H, Mohajjel Aghdam A, Rahmani A. Assessing Self-efficacy in Clinical Competence Among Nursing Students at Tabriz University of Medical Sciences. Educ Dev Jundishapur. 2015; 6(2): 107-14.

48. Joyce BR, Weil M, Calhoun E. Models of teaching. 8th ed. Boston, London: Pearson; 2008.

49. Baptista RC, Paiva LA, Goncalves RF, Oliveira LM, Maria de Fatima CR, Martins JC. Satisfaction and gains perceived by nursing students with medium and high-fidelity simulation: A randomized controlled trial. Nurse Education Today. 2016 Nov 1; 46: 127-32.

50. Sofer D. The Value of Simulation in Nursing Education. This clinical activity is transforming nursing training and practice. AJN REPORTS. 2018 April; 118(4): 17-18. 